\title{
INSTRUMENTOS BÁSICOS: ASPECTOS RELACIONADOS AO PROCESSO ENSINO APRENDIZAGEM NO CURSO DE GRADUAÇÃO DAS ESCOLAS DE ENFERMAGEM DA GRANDE SÃO PAULO *
}

\author{
Aidê Ferreira Ferraz"* \\ Maria José D'Elboux Diogo"* \\ Regina Márcia Cardoso de Souza"* \\ Vera Lúcia Conceição de Gouveia Santos** \\ Vera Lúcia Regina Maria**
}

FERRAZ, A. F.; DIOGO, M. J. D.; SOUZA, R. M. C. de; PEREZ, S. M.; SANTOS, V. L. C. de G.; MARIA, V. L. R. Instrumentos básicos: aspectos relacionados ao processo de ensino aprendizagem no curso de graduação das escolas de enfermagem da Grande São Paulo. Rev. Esc. Enf. USP, São Paulo, 22 (n. ${ }^{\circ}$ especial): 161-188, Jun. 1988.

Os Instrumentos Básicos de Enfermagem (IBE) têm sido ensinados durante anos na disciplina Fundamentos de Enfermagem dos Cursos de Graduação em Enfermargem, sem uma análise mais profunda da sua importância e repercussão na prática profissional. Em vista disso, as autoras desenvolveram este estudo, com objetivo de diagnosticar alguns aspectos do processo ensino-aprendizagem dos IBE, junto - a alunos e professores das Escolas de Enfermagem da Grande São Paulo. Dentre os resultados obtidos, salienta-se a comunicação e a observação como os IBE considerados mais importantes e mais empregados na prática, tanto por discentes como docentes. As autoras discutem ainda sobre aspectos estruturais do desenvolvimento desse conteúdo nas Escolas pesquisadas.

UNITERMOS: Ensino de enfermagem. Prática da enfermagem. Aprendizagem.

\section{INTRODUÇÃO:}

O estudo dos Instrumentos Básicos de Enfermagem (IBE) tem ocupado um importante espaço na disciplina de Fundamentos de Enfermagem III do Programa de Pós-Graduação - Nivel Mestrado, da Escola de Enfermagem da USP (EEUSP).

As discussões relativas aos IBE tiveram como base o conceito proposto por HORTA, ${ }^{1,2}$ que por sua vez fundamentou-se em definições pedagógicas (de instrumento e instrumental pedagógico) para a elaboração dos seguintes

\footnotetext{
- Trabalho apresentado à disciplina Fundamentos de Enfermagem III. Programa de P6s-Graduação, Nivel Mestrado da EEUSP.

- Enfermeiras: Alunas da disciplina Fundamentos de Enfermagem III. Programa de Pós-Graduaçãa, Nivel Mestrado da EEUSP.
} 
conceitos: "Instrumentos básicos (IB)são as habilidades, conhecimentos e atitudes indispensáveis para a execução de uma atividade" ${ }^{1} \mathrm{e}$ "instrumentos básicos de enfermagem são o conjunto de conhecimentos e habilidades fundamentais para o exercício de todas as atividades profissionais" 2.

A partir deste referencial e de outras discussões filosóficas, as autoras elaboraram o seu próprio conceito que se assemelha ao de HORTA 1.2 e enfocam a prática da enfermagem nos seus diversos aspectos: Instrumentos básicos são o conjunto de atitudes, habilidades e conhecimentos que fundamentam a formação e o exercício profissional do enfermeiro, fornecendo os subsídios essenciais à prestação da assistência, ao ensino e à pesquisa.

A importância do ensino dos IBE na formação do enfermeiro, já na graduação, foi enfaticamente defendida por HORTA ${ }^{2}$, constituindo um dos marcos teóricos no desenvolvimento do processo de Enfermagem.

HORTA ${ }^{2}$ propôs e aplicou uma metodologia de ensino Teórico-Prático (T/P) dos IBE, já em 1965, na disciplina de Fundamentos de Enfermagem para os alunos do curso de graduação, obtendo resultados bastante satisfatórios no desenvolvimento global dos estudantes, como: observações, mais objetivas, mais rápidas, significativas e numerosas; históricos de enfermagem mais completos; planos de cuidados melhor elaborados e executados; habilidades mais aprimoradas; trabalho em equipe mais harmonioso e produtivo; avaliações construtivas e objetivas e maior iniciativa e criatividade na resolução de problemas.

A partir dos resultados obtidos, já nessa época, HORTA ${ }^{2}$ propunha a inserção e manutenção do ensino de IBE nas disciplinas de Fundamentos de Enfermagem, das diversas escolas, de maneira integrada em todas as situações didáticas, com metodologia informal, prática e não dispendiosa ${ }^{2}$.

Após análise desses fatos e dos IBE especificamente, percebemos que eles permeiam o agir do enfermeiro, embora a sua formação e a prática profissional não estejam sendo embasados nestes instrumentos, surgindo daí questionamentos acerca da sua valorização no ensino e na prática, assim como a sua denominação como instrumento básico da enfermagem, uma vez que não são exclusivos desta profissão.

Ao considerarmos o tema, constatamos a escassez de bibliografia específica e notamos a existência de capítulos isolados referentes aos IBE nos livros-textos de Fundamentos de Enfermagem, parecendo serem importantes para os autores dentro da sua concepção de Enfermagem, embora não sejam denominados ou mesmo trabalhados como instrumentos básicos.

Os IBE adotados por nós, foram embasados nos indicados por HORTA*2, com algumas modificações baseados na própria história da inserção do conceito de IBE nos currículos de Enfermagem, e a partir daí, nas crenças

\footnotetext{
- NOTA: HORTA enumera como instrumentos básicos na Enfermagem: comunicação, observação, avaliação, trabalho em equipe, destreza manual, aplicação dos princípios científicos, criatividade, planejamento, método científico ou de resoluçāo de problemas e utilização dos Recursos da Comunidade.
} 
geradas em relação a eles. A alteração proposta situou-se basicamente na exclusão do IBE "utilização dos recursos da comunidade". Cabe lembrar, que Horta utilizou "aplicação de conhecimentos científicos" como primeira nomenclatura para o IBE, "aplicação de princípios científicos".

A partir desses aspectos comentados e considerando-se que:

- O curso de Gradução em Enfermagem é o ponto inicial da formação profissional e responsável por grande parte dos conceitos, valores, atitudes, crenças, conhecimento científico e técnico desenvolvidos pelo enfermeiro;

- Existe uma grande defasagem entre a formação teórica do aluno de enfermagem e a prática do enfermeiro no campo, também em relação à aplicação dos IBE;

- Há escassez de referencial teórico específico sobre IBE;

- Há cerca de 20 anos, Horta já propunha estudos para o desenvolvimento do tema, relativo à validade e à identificação de novos IBE;

- Sentimos a necessidade de elaborar um estudo voltado para o processo ensino-aprendizagem desses instrumentos, que viesse subsidiar discussões mais profundas acerca do assunto e que proporcionasse uma visão realista do preparo dos enfermeiros a nível de graduação, até de verificar os diferentes enfoques de professores e alunos sobre o tema.

$O$ trabalho foi desenvolvido com os seguintes objetivos:

\section{OBJETIVO GERAL:}

Verificar aspectos relacionados ao processo ensino-aprendizagem dos instrumentos básicos de enfermagem no curso de graduação das escolas de Enfermagem da Grande São Paulo.

\section{OBJETIVOS ESPECÍFICOS:}

2.1. Em relação ao professor: Verificar:

2.1.1. qual a disciplina que ministra IBE;

2.1.2. quais os IBE ensinados;

2.1.3. como são ensinados os IBE na teoria e na prática;

2.1.4. quais as dificuldades encontradas nesse ensino;

2.1.5. qual a carga horária total destinada ao ensino desses instrumentos;

2.1.6. quais os objetivos do ensino desse instrumentos e a importância a eles atribuída.

2.2. Em relação ao aluno: verificar o conhecimento dos alunos do 4. ${ }^{\circ}$ semestre do curso de graduação em Enfermagem das Escolas de Enfermagem da Grande São Paulo, quanto a:

2.2.1. conceituação de IBE; 
2.2.2. identificação dos IBE;

2.2.3. importância atribuída aos IBE;

2.2.4. aplicação prática do IBE no campo.

\section{METODOLOGIA}

\section{POPULAÇÃO}

A população do estudo foi constituída por alunos do $4 .^{\circ}$ semestre do Curso de Graduação em Enfermagem e professores da disciplina que introduzem o ensino de IBE no Curso de Graduação das Escolas de Enfermagem da Grande São Paulo.

A coleta de dados foi realizada entre $31 / 10 / 86$ a $14 / 11 / 86$, e foram incluídos todos os alunos e professores que atenderam aos critérios descritos a seguir:

1.1. Professores

- Um professor que tivesse ministrado IBE para alunos que, na época do estudo, cursavam o $4 .^{\circ}$ semestre do Curso de Graduação.

1.2. Alunos

- Que estivessem cursando o 4..$^{\circ}$ semestre do Curso de Graduação em Enfermagem, no período da coleta de dados.

- Que houvessem cursado na mesma Escola, a disciplina em que é introduzido o ensino dos IBE.

- Que estivessem presentes em sala de aula no dia estabelecido para a coleta de dados.

\section{INSTRUMENTOS DE COLETA DE DADOS}

A coleta de dados foi feita utilizando-se 2 tipos de instrumentos: um para os professores e outro para os alunos.

$\mathrm{O}$ instrumento utilizado para os professores foi o formulário (anexo I), contendo 7 questões referentes a informações sobre a disciplina, $n .^{\circ}$ de professores e alunos, carga horária e ensino dos IBE.

$O$ instrumento utilizado para os alunos foi o questionário (anexo II) com 4 questões, acerca dos conceitos e conhecimentos dos alunos quanto aos IBE.

\section{PROCEDIMENTO PARA A COLETA DE DADOS}

Para a realização da coleta de dados, inicialmente fizemos um levantamento das Escolas de Enfermagem existentes na Grande São Paulo, sendo constatado um total de sete escolas. Destas, somente em uma, não foi possivel a realização do estudo, pela inviabilidade de aplicação do instrumento de coleta de dados para os alunos, que já não desenvolviam atividades em grupo, nessa época do ano. 
Em seguida, estabelecemos contato com docente destas escolas para levantamento do número de alunos do $4 .^{\circ}$ semestre do Curso de Graduação em enfermagem, e identificação do professor responsável pelo ensino destes IBE, àqueles alunos.

Das seis escolas pesquisadas, obtivemos os seguintes totais de alunos matriculados no $4 .^{\circ}$ semestre do Curso de Graduação:

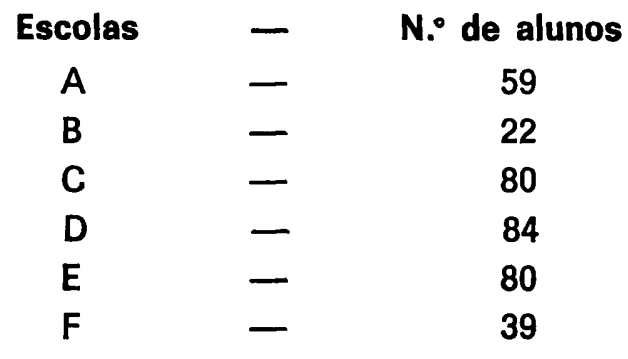

Posteriormente, foi elaborado e encaminhado ofício às diretoras das Escolas expondo os objetivos do trabalho e solicitando permissão para a sua realização. Simultaneamente, entramos novamente em contato por telefone com os docentes já indicados, para o estabelecimento de uma data específica para a coleta de dados, tanto com os alunos quanto com os professores.

Cabe ressaltar que, precedendo à coleta de dados propriamente dita, fizemos um pré-teste de ambos instrumentos, sendo realizadas pequenas modificações de ordem semântica, para maior facilidade de compreensão.

Efetuamos a coleta de dados, que consistiu de entrevista única (Anexo I) com o docente que atendesse ao critério já descrito, e da aplicação de questionários (Anexo II) junto aos alunos, cujos fatores de inclusão já foram mencionados.

Por ocasião da aplicação dos questionários, não foram dados aos alunos quaisquer esclarecimentos adicionais sobre IBE, além das seguintes orientações:

- não deveriam responder aos questionários aqueles alunos que não tivessem cursado, naquela escola, a disciplina na qual eram ensinados os IBE (segundo critério para o estabelecimento da população);

- as questões não respondldas deveriam ser assinaladas com um traço e

- todos os questionários teriam que ser devolvidos, mesmo que não preenchidos.

\section{TRATAMENTO ESTATISTICO}

Os dados obtidos serão apresentados em tabelas, quadros e gráficos, com freqüências absoluta e relativa. 


\section{RESULTADOS E DISCUSSÃO}

Os resultados foram trabalhados em duas etapas, a primeira relativa às respostas dos professores e a segunda, às respostas dos alunos.

\section{Professores}

Nas seis escolas de enfermagem da Grande São Paulo onde efetuamos este estudo, os IBE têm sido ministrados no segundo semestre do curso de graduação, havendo variação quanto à nomenclatura empregada em cada escola: Fundamentos de Enfermagem I, Fundamentos de Enfermagem, Introdução à Enfermagem I e Introdução à Enfermagem.

Em relação ao número de professores responsáveis pela Unidade referente aos IBE, houve variação de 01 a 04 docentes, tendo havido coincidência apenas numa das escolas (C), entre este número e o número total de professores da disciplina.

\section{QUADRO I}

Relação dos I.B.E. ensinados nas escolas de Enfermagem da Grande São Paulo, 1986

\begin{tabular}{|c|c|c|c|c|c|c|}
\hline \multirow[b]{2}{*}{ IBE } & \multicolumn{6}{|c|}{ ESCOLAS } \\
\hline & $A$ & B & $\mathrm{C}$ & $D$ & $E$ & $F$ \\
\hline 1 - Observação & $x$ & $x$ & $x$ & $x$ & $x$ & $x$ \\
\hline 2 - Comunicação & $x$ & $x$ & $x$ & $x$ & $x$ & - \\
\hline 3 - Destreza manual & $x$ & $x$ & $x$ & $x$ & $x$ & - \\
\hline 4 - Criatividade & $x$ & $x$ & $x$ & $x$ & $x$ & - \\
\hline 5 - Aplicação dos Princípios Científicos & $x$ & $x$ & $x$ & $x$ & $x$ & - \\
\hline 6 - Método científico & $\mathrm{x}$ & 一 & - & $\mathbf{x}$ & $\mathbf{x}$ & - \\
\hline 7 - Planejamento & $x$ & $x$ & $x$ & $x$ & $x$ & - \\
\hline 8 - Trabalho em equipe & $x$ & $x$ & $x$ & $x$ & $x$ & - \\
\hline 9 - Avaliação & $x$ & - & $x$ & $x$ & $x$ & - \\
\hline
\end{tabular}

$$
\text { LEGENDA: } \begin{aligned}
x & =\text { Sim } \\
- & =\text { Năo }
\end{aligned}
$$

Em relação aos IBE que compõem o conteúdo programático dessa Unidade, notamos através do QUADRO I que a observação é o Único IBE ensinado em todas as Escolas de Enfermagem estudadas, sendo também o único ministrado na Escola F. 
A avaliação, por sua vez, só aparece em 04 escolas (A, C, D, e E) e o Método Científico em 03 destas ( $A, D$ e E).

Verificamos ainda que todos os IBE ensinados nas escolas estudadas estão entre os designados por HORTA ${ }^{1}$.

\section{QUADRO II}

Relação da carga horária total da disciplina onde são ensinados os IBE e carga horária destinada aos IBE, na teoria e na prática, 1986

\begin{tabular}{|c|c|c|c|c|}
\hline \multirow[b]{2}{*}{ Escolas } & \multicolumn{3}{|c|}{ Carga horária destinada aos IBEs } & \multirow[b]{2}{*}{$\begin{array}{l}\text { Carga horária total } \\
\text { da disciplina }\end{array}$} \\
\hline & Teórica & Prática & $\begin{array}{c}\text { Carga horária total } \\
\text { para os IBEs }\end{array}$ & \\
\hline A & 02 & 03 & $05(7,35 \%)$ & $68(100 \%)$ \\
\hline B & 08 & - & $08(10 \%)$ & $80(100 \%)$ \\
\hline 0 & 24 & 36 & $60(50 \%)$ & $120(100 \%)$ \\
\hline D & 12 & - & $12(20 \%)$ & $60(100 \%)$ \\
\hline E & 18 & 一 & $18(17,30 \%)$ & $104(100 \%)$ \\
\hline $\mathbf{F}$ & 12 & 08 & $20(27,77 \%)$ & $72(100 \%)$ \\
\hline
\end{tabular}

Os dados do Quadro II nos mostram que a carga horária destinada ao desenvolvimento da Unidade dos IBE variou de 7 a $50 \%$ da carga horária total da disciplina na qual está inserida, o que pode indicar a maior ou menor relevância atribuída ao tema.

Dentre as escolas estudadas, 03 distribuem as horas disponiveis para essa Unidade entre teoria e prática e as demais somente utilizam o ensino teórico.

As estratégias empregadas para o ensino teórico constaram principalmente de aula expositiva, além de outras técnicas como por exemplo, estudos em grupo e seminários. Quanto ao ensino prático, os professores das diversas escolas utilizaram-se da representação, prática em campo de estágio e execução de técnicas em laboratório.

Os professores das escolas estudadas, enumeraram algumas dificuldades sentidas no processo ensino-apredizagem dos IBE. O professor da Escola $B$ foi o único a referir não ter qualquer problema nesse sentido.

Quanto às dificuldades gerais relatadas, temos:

- ausência de bibliografia específica e fácil;

- necessidade de aplicação de conhecimentos de outras disciplinas; 
- elevada proporção de alunos por professor;

- difícil associação dos IBE pelos alunos à prática e à realidade;

- reduzida carga horária;

- imaturidade do aluno e

- dificuldade de compreensão por parte dos alunos.

Além destas, foram mencionadas outras dificuldades relacionadas ao ensino de alguns IBE específicos, tais como: aplicação dos princípios científicos, destreza manual, avaliação, método científico e criatividade.

Quanto aos objetivos do ensino dos IBE nas escolas, os professores fundamentaram-se principalmente na importância destes para o desenvolvimento profissional.

\section{QUADRO III}

Relação das respostas dos professores das escolas de Enfermagem da Grande São Paulo, quanto aos IBEs mais empregados pelo aluno na prática, 1986

IBE

\section{ESCOLAS}

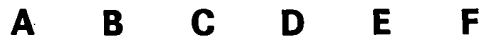

Observação

Comunicação

Destreza manual

Criatividade

Aplicação dos princípios científicos

Método Científico

Planejamento

Trabalho em equipe

Avaliação

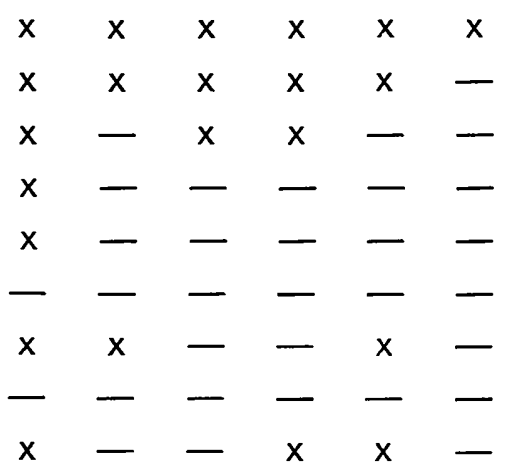

LEGENDA: $X=\operatorname{Sim}$

$$
\text { - = Não }
$$

Segundo os dados do QUADRO III, os professores das seis escolas de enfermagem, apontaram a observação como o instrumento básico mais utilizado na prática pelo aluno de Enfermagem. A comunicação foi indicada em cinco destas escolas. Já o mćtodo científico e o trabalho em equipe, não foram citados por professores de quaisquer das escolas, neste item. 


\section{GRAFICO I}

Representação das respostas dos professores das Escolas de Enfermagem da Grande São Paulo quanto aos IBE mais importantes, 1986
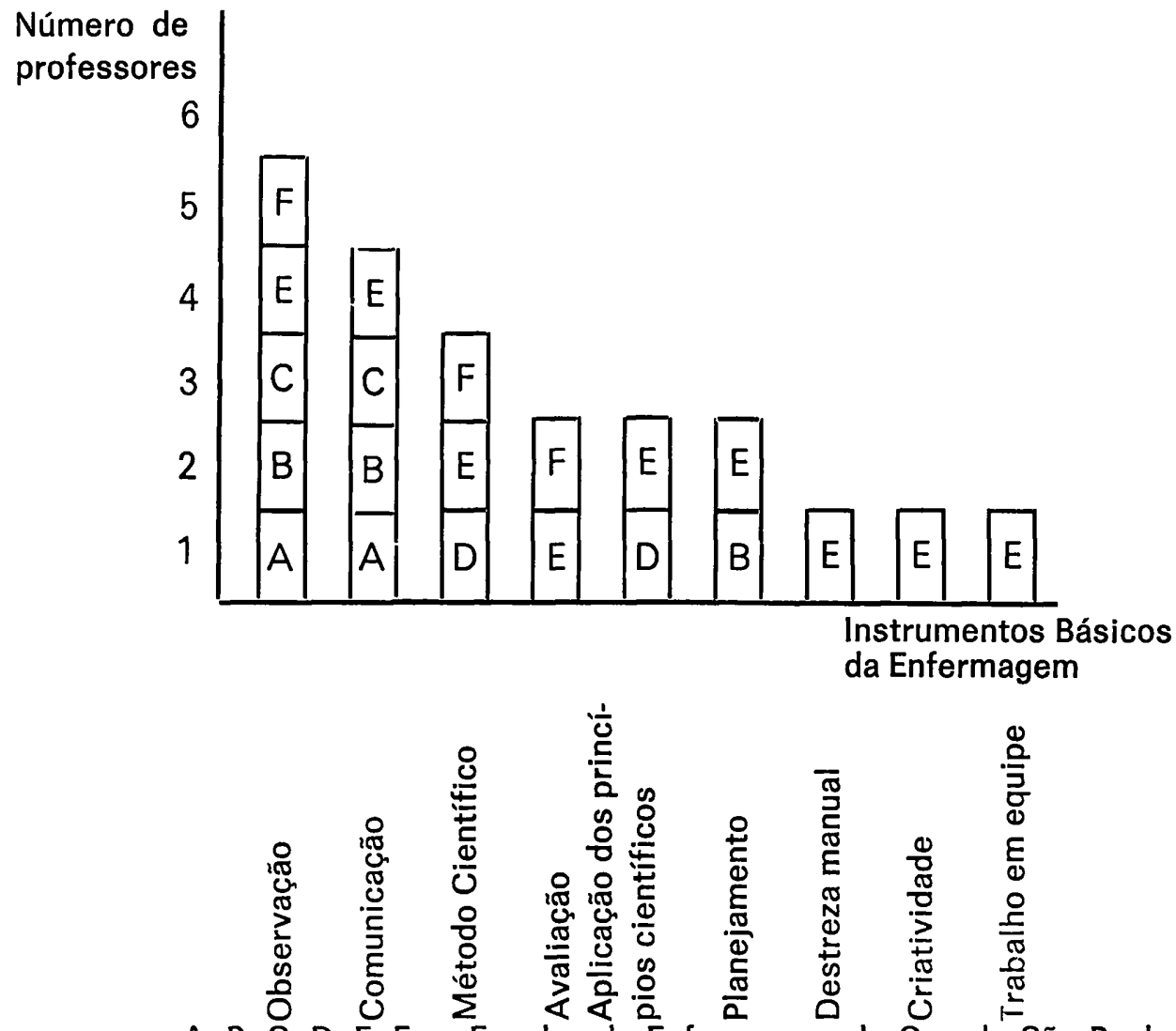

A, B, C, D, E, F = Escolas de Enfermagem da Grande São Paulo.

Segundo as figuras do GRAFICO I, podemos constatar que o IBE considerado como mais importante pela maioria dos professores é a observação, seguida da comunicação (citada por 04 docentes) e do Método Científico (mencionado por 03 professores). Os IBE restantes foram citados com menor freqüência.

Observamos ainda que o professor da Escola $E$ indicou todos os IBE como importantes para a prática profissional.

\section{Alunos}

Considerando a metodologia proposta para a coleta de dados junto aos alunos das diversas escolas de Enfermagem da Grande São Paulo, apresentamos a seguir o quadro demonstrativo do número de alunos respondentes em relação ao número de alunos matriculados no $4 .^{\circ}$ semestre do curso de graduação.

Cumpre-nos esclarecer que consideramos como respondentes, aqueles alunos que responderam a pelo menos uma das questōes do instrumento de coleta de dados. (Anexo II). 
Número de alunos respondentes, em relação ao número de alunos

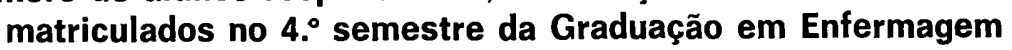
em cada uma das Escolas da Grande São Paulo, 1986.

\begin{tabular}{llllllll}
\hline Escolas & A & B & C & D & E & F & Total \\
\hline $\begin{array}{l}\text { Número de alunos } \\
\text { matriculados }\end{array}$ & 59 & 22 & 80 & 84 & 80 & 39 & 364 \\
$\begin{array}{l}\text { Número de respon- } \\
\text { dentes }\end{array}$ & 39 & 14 & 23 & 23 & 11 & 28 & 138 \\
$\begin{array}{l}\% \text { de respondentes } \\
\text { em relação ao nú- }\end{array}$ & & & & & & & \\
$\begin{array}{l}\text { mero de alunos ma- } \\
\text { triculados }\end{array}$ & 66,10 & 63,64 & 28,75 & 27,38 & 13,75 & 71,80 & 37,91 \\
\hline
\end{tabular}

Dos 364 alunos matriculados no Curso de Graduação das 06 escolas pesquisadas, 138 ou $37,91 \%$ responderam total ou parcialmente os questlonários.

As escolas $A, B$ e $F$ apresentaram maiores percentuais de alunos respondentes $(66,10 \% ; 63,64 \%$ e $71,80 \%$ respectivamente).

$\mathrm{Na}$ maioria das escolas, os alunos do $4 .^{\circ}$ semestre estavam subdivididos em duas ou três disciplinas paralelas, sendo que a aplicação dos questionários foi realizada para um ou dois desses grupos, à exceção das escolas $A$ e $D$, onde todos os alunos estavam reunidos para a aplicação do questionário.

A análise dos conceitos elaborados pelos alunos das Escolas de Enfermagem da Grande São Paulo, mostrou-nos que estes englobavam dois aspectos: um referente à caracterização do termo IBE e outro aos objetivos da sua utilização na Enfermagem.

Quanto aos objetivos do emprego dos IBE citados pelos alunos, mostraram-se altamente diversificados, abrangendo desde a melhoria da assis. tência, atendimento das necessidades humanas básicas e desenvolvimento profissional, até aspectos específicos da própria assistência e direcionamento para a aplicação prática de alguns dos instrumentos. Independentemente, porém, da forma com que foram expressos, todos os objetivos denotavam em maior ou menor amplitude, a importância dos IBE, para a Enfermagem.

Para a elaboração da tabela I foram utillzados somente os dados relaclonados à caracterização do tema (IBE), uma vez que os consideramos a essência do conceito. 


\section{TABELA I}

Conceitos dos IBE apresentados pelos alunos das Escolas de Enfermagem da Grande São Paulo, 1986.

\begin{tabular}{|c|c|c|c|c|c|c|c|}
\hline \multirow[b]{2}{*}{ Conceitos } & \multicolumn{7}{|c|}{ Escolas } \\
\hline & A & B & $\mathrm{C}$ & $D$ & $E$ & $F$ & Total \\
\hline - Sinonímia & 24 & - & 15 & 20 & 11 & 15 & $\begin{array}{c}85 \\
(64.88 \%)\end{array}$ \\
\hline - "Tudo" & 07 & 04 & 04 & 02 & 一 & 一 & $\begin{array}{c}17 \\
(12,98 \%)\end{array}$ \\
\hline - Conhecimento & 一 & 03 & 一 & 一 & 一 & 05 & $\begin{array}{c}08 \\
(6,11 \%)\end{array}$ \\
\hline - Atitudes & 01 & 一 & 01 & - & - & 一 & $\begin{array}{c}02 \\
(1,53 \%)\end{array}$ \\
\hline $\begin{array}{l}\text { - Conhecimentos e meios } \\
\text { - Conhecimentos desenvoltura }\end{array}$ & 01 & 一 & 一 & 一 & 一 & 一 & $\begin{array}{c}01 \\
(0,76 \%\end{array}$ \\
\hline postura, habilidades & 01 & 一 & - & - & - & 一 & $\begin{array}{c}01 \\
(0,76 \%)\end{array}$ \\
\hline - Conhecimentos e habilidades & 一 & 01 & 一 & 一 & 一 & 一 & $\begin{array}{c}01 \\
(0,76 \%)\end{array}$ \\
\hline - Outros & 一 & 05 & 02 & - & 一 & 06 & $\begin{array}{c}13 \\
(9,92 \%)\end{array}$ \\
\hline - Não responderam & - & 02 & 01 & - & - & 一 & $\begin{array}{l}03 \\
(2,30 \%\end{array}$ \\
\hline Total & & & & & & & $\begin{array}{c}131 \\
(100 \%) \\
\end{array}$ \\
\hline
\end{tabular}

\section{LEGENDA:}

SINONIMIA DE INSTRUMENTOS BASICOS:

- Necessidades

- Subsídios

- Instrumentos

- Medidas

- Princípios

- Meios

- Elementos

- Recursos

- Mecanismos

- Embasamento

- Base

- Requisitos

- Métodos

\section{OUTROS:}

- O que há de mais importante

- Levantamento das necessidades humanas básicas

- Objetos de uso

- Cuidados

- Princípios científicos e éticos

- Exógeno e endógeno

- Informações necessárias

- Material

- Primeiros cuidados

- Melhoria do atendimento

- Maneira pela qual pode-se observar o paciente

- Conhecimento e responsabilidade

- Melhoram a patologia do paciente 
A tabela I mostra que a maioria dos alunos $(64,88 \%)$ conceituou IBE através de termos que agrupamos no item "sinonímia", por constituírem sinônimos de "instrumentos" (recursos, meios) ou palavras empregadas com significado semelhante (mecanismos, elementos, princípios, métodos) ou ainda como a fundamentação da própria Enfermagem (base, embasamento). Logo a seguir, apareceu o termo "tudo", como o segundo conceito mais citado $(12,98 \%)$.

Reconhecemos que o aparecimento de sinônimos ou da palavra "tudo" na conceituação de Instrumentos Básicos feita pelos alunos, pode ser devido à amplitude dessa terminologia bem como à obviedade da definição presente no próprio termo "instrumentos básicos", a qualquer área do conhecimento a que se aplique.

Vale ressaltar que o aparecimento de elementos componentes do conceito de IBE, segundo HORTA ${ }^{2}$, ocorreu em baixa freqüência e esporadicamente em 4 (quatro) escolas diferentes: atitudes $(1,53 \%)$, conhecimentos $\mathrm{e}$ habilidades $(0,76 \%)$ e conhecimento $(6,11 \%)$.

Com relação à abrangência desse conceito, somente 01 aluno da Escola $A(0,76 \%)$ mencionou as 3 áreas nele contidas (atitude: desenvoltura, postura, habilidade e conhecimentos).

Consideramos não terem respondido à questão, aqueles alunos $(2,30 \%)$ que só expressaram em suas respostas os objetivos da utilização dos IBE.

Como pode ser visto na tabela II, obtivemos 741 respostas dos alunos, sendo que 2 dos alunos respondentes deixaram em branco esta questão.

Verificamos que na maioria das respostas dos alunos $(67,07 \%)$, foram indicados como instrumentos básicos, aqueles preconizados por HORTA , enquanto que $21,32 \%$ das respostas não se referiam a estes e $11,61 \%$ correspondiam a itens apenas relacionados aos instrumentos. Constatamos também que, princípios científicos e observação obtiveram o maior número de itens a eles relacionados enquanto que as demais respostas distribuiram-se equitativamente entre os outros instrumentos. (Anexo III).

Os alunos das escolas $D$ e $E$ não apresentaram respostas desvinculadas aos instrumentos básicos segundo a proposição de HORTA, enquanto as resposats obtidas nas escolas $B$ e $F$, totalizaram maior número de itens não relacionados aos $\operatorname{IBE}(3,24 \%$ e $7,56 \%$ respectivamente) do que de $\mathrm{IBE}$ propriamente ditos $(2,70 \%$ e $4,86 \%$ respectivamente nessas escolas $)$.

Ao analisarmos o total de respostas por escola, observamos que aquelas que apresentaram maior número de respostas foram as escolas $A$ e $C$, porém a escola $A$ também apresentou o maior índice de "itens não-relacionados" $73(9,85 \%)$.

Com relação aos "itens não-relacionados aos IBE", obtivemos 158 respostas $(21,32 \%)$ que se distribuíram equitativamente quanto à classificação por nós elaborada: Fases da Metadologia de Assistência e Necessidades humanas Básicas; valores morais e atitudes na Enfermagem e Recursos Materiais e equipamentos. (Anexo IV). 


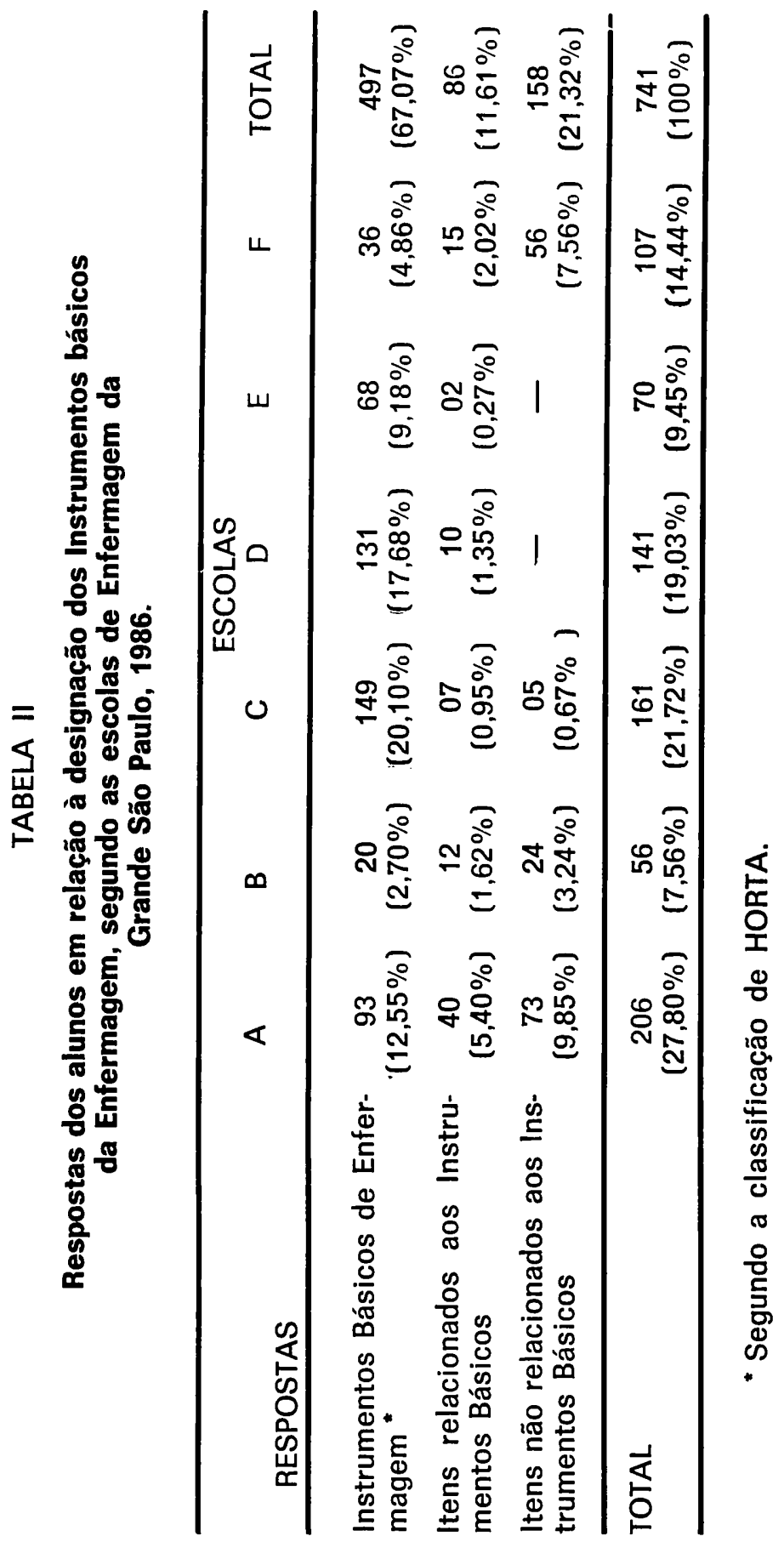

Rev. Esc. Ent. USP, São Paulo, 22 (n. ${ }^{\circ}$ especial), 161-188, jun. 1988. 


\section{QUADRO V}

Referente à média de IBE citados, por aluno, segundo as Escolas de Enfermagem da Grande São Paulo, 1986

$\begin{array}{lcccccc}\text { Escolas } & \text { A } & \text { B } & \text { C } & \text { D } & \text { E } & \text { F } \\ \begin{array}{l}\text { Número de respondentes } \\ \begin{array}{l}\text { Número de respostas cor- } \\ \text { retas * }\end{array}\end{array} & 93 & 14 & 23 & 23 & 11 & 28 \\ \begin{array}{l}\text { Média de respostas cer- } \\ \text { tas/aluno respondente }\end{array} & 2,39 & 1,43 & 6,48 & 5,69 & 6,18 & 1,28\end{array}$

"Consideramos como "respostas corretas" aqueles IBE que coincidiram com aqueles propostos por HORTA.

Ao analisarmos o número total de respostas relativas dos IBE dadas pelos alunos de cada escola, observamos que a maior média por aluno $(6,48)$, foi obtida pelos respondentes da escola $C$, seguida pelos índices alcançados pelos alunos das escolas $E(6,18)$ e $D(5,69)$.

Em relação às menores médias, foram aquelas apresentadas pelas escolas $B(1,43)$ e $F(1,28)$.

\section{TABELA III}

Distribuição das respostas dos alunos das Escolas de Enfermagem da Grande São Paulo, segundo indicação dos IBE, 1986

\begin{tabular}{|c|c|c|c|c|c|c|c|}
\hline IBE & A & B & $\begin{array}{l}\text { ESCO } \\
\mathrm{C}\end{array}$ & $\begin{array}{l}\text { LAS } \\
D\end{array}$ & $E$ & $F$ & TOTAL \\
\hline Observação & 31 & 10 & 22 & 19 & 11 & 13 & $106(21,33 \%)$ \\
\hline Comunicação & 20 & 04 & 18 & 21 & 11 & 14 & $88(17,71 \%)$ \\
\hline $\begin{array}{l}\text { Destreza Manual } \\
\text { Aplicacão dos Princípios }\end{array}$ & 09 & 04 & 23 & 22 & 01 & 04 & $63(12,68 \%)$ \\
\hline $\begin{array}{l}\text { Científicos } \\
\text { Método científico ou de }\end{array}$ & 01 & - & 15 & 02 & 04 & - & $22(4,43 \%)$ \\
\hline Resolução de Problemas & - & 01 & - & 18 & 07 & 01 & $27(5,43 \%)$ \\
\hline Planejamento & 26 & - & 15 & 10 & 10 & 02 & $63(12,68 \%)$ \\
\hline Trabalho em equipe & - & - & 19 & 05 & 04 & - & $28(5,63 \%)$ \\
\hline Avaliação & - & - & 18 & 15 & 10 & 02 & $45(9,05 \%)$ \\
\hline Criatividade & 06 & 01 & 19 & 19 & 10 & 一 & $55(11,06 \%)$ \\
\hline TOTAL & 93 & 20 & 149 & 131 & 68 & 36 & $(100 \%)$ \\
\hline
\end{tabular}


A tabela III refere-se à indicação dos IBE pelos alunos de cada uma das escolas em estudo.

Dentre os IBE, a observação e a comunicação obtiveram maiores percentuais de citação $21,33 \%$ e $17,71 \%$, respectivamente.

Os IBE menos citados foram: Aplicação de princípios científicos $(4,43 \%)$, Método Científico ou de Resolução de problemas $(5,43 \%)$ e Trabalho em equipe $(5,63 \%)$.

Vale ressaltar que apesar da Aplicação de princípios científicos ter sido o instrumento básico menos citado, constatamos que este obteve a maioria das respostas nos itens relacionados. (Anexo III).

A escola $B$ apresentou maior número de instrumentos não citados (4), seguida pelas escolas A e $F(3)$ enquanto que as escolas $D$ e $E$ apresentaram citações de todos os instrumentos básicos.

Quanto aos IBE citados pelos alunos como sendo os mais utilizados na prática (tabela IV), encontramos a observação $(28,08 \%)$, a comunicação $(16,72 \%)$, a destreza manual $(14,51 \%)$ e o planejamento $(11,67 \%)$.

Os restantes, criatividade $(7,25 \%)$, método científico ou de resolução de problemas $(5,36 \%)$, trabalho em equipe $(5,36 \%)$ e a avaliação $(6,00 \%)$, distribuíram-se equitativamente em relação à freqüência com que foram mencionados.

Analisando-se as respostas por escola, constatamos que a observação apareceu como a mais citada em 5 das 6 escolas pesquisadas. $\mathrm{Na}$ escola $D$, a destreza manual foi o instrumento que obteve maior número de respostas quanto à utilização na prática.

Ressaltamos que alguns alunos responderam que "todos os IBE são utilizados na prática", e nestes casos as respostas foram distribuídas nos diversos IBE citados por eles na $2 .^{\circ}$ questão do instrumento de coleta de dados.

Destacamos ainda que as escolas $\mathrm{B}$ e $\mathrm{F}$ apresentaram menores percentuais de repostas $(4,73 \%$ e $7,89 \%$ respectivamente) quanto aos IBE mais utilizados na prática, já que cerca de metade de suas respostas foram inseridas nos "itens não relacionados a IBE".

Para a elaboração da tabela $V$, consideramos como prioridade a ordem de importância atribuída pelos estudantes, quando da enumeração dos instrumentos básicos. Dentre as nove graduações obtidas optamos por analisar somente as 4 primeiras (da $1 .^{\circ}$ à $4 .^{\circ}$ prioridade).

Os dados da tabela $V$ mostram-nos que a observação é o instrumento básico considerado pelos respondentes como o mais importante, já que o citaram numa maior freqüência em $10^{\text {a }}$ prioridade $(32,74 \%)$. Seguem-se a este, a Comunicação $(15,05 \%)$, a Aplicação dos Princípios Científicos $(12,39 \%)$ e Planejamento $(11,51 \%)$ com percentuais bastante próximos. 


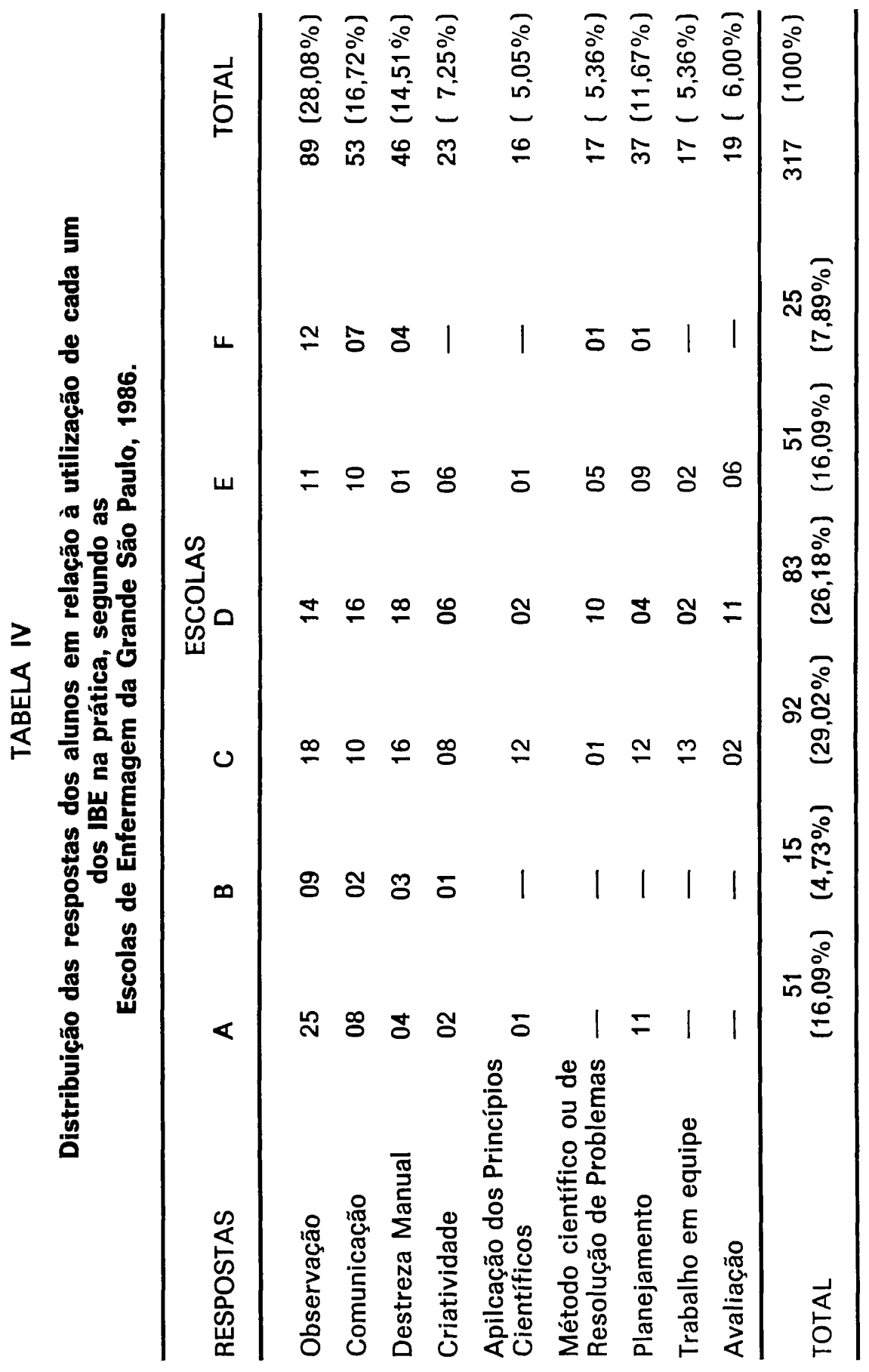


TABELA V

Distribuição dos IBE segundo a escala de prioridade estabelecida pelos alunos das Escolas de Enfermagem da Grande São Paulo, 1986.

\begin{tabular}{|c|c|c|c|c|}
\hline IBE & $\begin{array}{l}\text { PRIOR } \\
1 .\end{array}$ & $\begin{array}{c}\text { IDADES } \\
2{ }^{\circ}\end{array}$ & $3 .^{\circ}$ & 4. \\
\hline Observação & $\begin{array}{c}37 \\
(32,74 \%)\end{array}$ & $\begin{array}{c}24 \\
(36,36 \%)\end{array}$ & $\begin{array}{c}13 \\
(21,31 \%)\end{array}$ & $\begin{array}{c}11 \\
(20,00 \%)\end{array}$ \\
\hline Comunicação & $\begin{array}{c}17 \\
(15,05 \%)\end{array}$ & $\begin{array}{c}15 \\
(22,73 \%)\end{array}$ & $\begin{array}{c}13 \\
21,31 \%)\end{array}$ & $\begin{array}{c}12 \\
(21,82 \%)\end{array}$ \\
\hline Destreza manual & $\begin{array}{c}06 \\
(5,31 \%)\end{array}$ & $\begin{array}{c}06 \\
(9,09 \%)\end{array}$ & $\begin{array}{c}08 \\
(13,11 \%)\end{array}$ & $\begin{array}{c}08 \\
(14,54 \%)\end{array}$ \\
\hline Planejamento & $\begin{array}{c}13 \\
(11,51 \%)\end{array}$ & $\begin{array}{c}07 \\
(10,61 \%)\end{array}$ & $\begin{array}{c}15 \\
(24,59 \%)\end{array}$ & $\begin{array}{c}05 \\
(9,09 \%)\end{array}$ \\
\hline Método científico & $\begin{array}{c}09 \\
(7,96 \%)\end{array}$ & $\begin{array}{c}04 \\
(6,06 \%)\end{array}$ & $\begin{array}{c}03 \\
(4,92 \%)\end{array}$ & $\begin{array}{c}04 \\
(7,28 \%)\end{array}$ \\
\hline Avaliação & $\begin{array}{c}05 \\
(4,42 \%)\end{array}$ & $\begin{array}{l}05 \\
(7,58 \%\end{array}$ & $\begin{array}{c}05 \\
(8,20 \%)\end{array}$ & $\begin{array}{c}08 \\
(14,54 \%)\end{array}$ \\
\hline $\begin{array}{l}\text { Aplicação dos Princípios } \\
\text { Científicos }\end{array}$ & $\begin{array}{c}14 \\
(12,39 \%)\end{array}$ & 一 & 一 & - \\
\hline Trabalho em equipe & $\begin{array}{c}06 \\
(5,31 \%)\end{array}$ & $\begin{array}{l}02 \\
(3,03 \%\end{array}$ & $\begin{array}{c}03 \\
(4,92 \%)\end{array}$ & $\begin{array}{c}05 \\
(9,09 \%)\end{array}$ \\
\hline Criatividade & $\left(\begin{array}{c}06 \\
(5,31 \%)\end{array}\right.$ & $\begin{array}{c}03 \\
(4,54 \%)\end{array}$ & $\begin{array}{c}01 \\
(1,64 \%)\end{array}$ & $\begin{array}{c}02 \\
(3,64 \%)\end{array}$ \\
\hline TOTAL & $\begin{array}{c}113 \\
(100 \%)\end{array}$ & $\begin{array}{c}66 \\
(100 \%)\end{array}$ & $\begin{array}{c}61 \\
(100 \%)\end{array}$ & $\begin{array}{c}55 \\
(100 \%)\end{array}$ \\
\hline
\end{tabular}

Com relação às $2 .^{\mathrm{a}}, 3$. $^{\mathrm{a}}$ e 4 . $^{\mathrm{a}}$ prioridades, constatamos que a Observação e a Comunicação têm repetidamente os índices mais elevados que os demais instrumentos básicos. Estes são superados somente na $3 .^{a}$ prioridade, pelo Planejamento, e mesmo assim por uma discreta diferença $(24,59 \%)$.

Vale ressaltar que todos os instrumentos básicos aparecem nas 4 prioridades, exceto a Aplicação de Princípios Científicos que foi mencionada somente na $1 .^{\circ}$ prioridade.

Notamos, ainda, que:

2.1. Observação - apareceu em todas as escolas entre a 1." e 4." prioridades.

2.2. Comunicação - apareceu em todas as escolas entre a $1 .^{a}$ e $4 .^{a}$ prioridades. 
2.3. Destreza manual - apareceu em todas as escolas entre a $1 .^{\mathrm{a}}$ e $4 .^{\circ}$ prioridades.

2.4. Planejamento - não foi citada somente pela escola B entre as 4 prioridades.

2.5. Método científico - não foi citada somente pela escola $A$ entre as 4 prioridades.

2.6. Avaliação - não foi citada pelas escolas A, B e F.

2.7. Princípios científicos - não foi citado pelas escolas $B, E$ e $F$.

2.8. Trabalho em equipe - não foi citado pelas escolas $A, B$ e $F$.

2.9. Criatividade - não foi citada pelas escolas $B$ e $F$.

Quanto à priorização dos instrumentos básicos, podemos constatar que os alunos da escola $A$ e escola $E$, citaram a observação com maior freqüência em $1 .^{a}$ prioridade.

Quanto à escola $B$, o gráfico nos revela que a observação foi o único instrumento citado em primeira prioridade e mesmo assim em baixa freqüência.

Observamos que os alunos da escola $C$, apesar de terem dado um grande destaque para a aplicação dos princípios científicos em 1. prioridade, também citaram comunicação, observação e trabalho em equipe nesta prioridade, de forma equitativa e representativa.

$\mathrm{Na}$ escola $\mathrm{D}$, os seguintes IBE: observação, comunicação e método científico, foram mencionados numa freqüência similar, na $1 .^{\mathrm{a}}$ prioridade. Com referência à Escola $F$, os discentes indicaram a observação como 1. a prioridade. Além deste, a comunicação e o planejamento foram os únicos IBE citados nesta prioridade, embora com baixa freqüência.

Cabe ressaltar que várias outras respostas foram dadas, na tentativa de priorizar os IBE, porém, uma vez que se enquadravam nos "itens relacionados" e "não relacionados" aos IBE, não constaram das análises desta questão.

\section{Professores e Alunos}

Os resultados obtidos revelaram-nos que todas as escolas da Grande São Paulo pesquisadas, dedicam um determinado espaço de sua carga horária teórico-prática ao ensino dos IBE, dentro de uma disciplina cuja nomenclatura e número de professores disponíveis variaram conforme a escola. Porém, esta disciplina estava sempre inserida no $2 .^{\circ}$ semestre do curso de graduação.

Ao analisarmos as cargas horárias destinadas ao ensino dos IBE (Quadro II) parecem-nos não terem influenciado sensivelmente nas respostas dos alunos quanto à enumeração dos IBE (tabela II). Esta afirmação pode ser feita ao observarmos que as escolas $C, D$ e $E$, apesar de não disporem 
de cargas horárias semelhantes (quanto ao número total de horas e distribuição $T / P$ ), comportaram-se de forma similar quanto à média de respostas corretas por aluno (Quadro $V$ ) e ao número de itens não-relacionados aos IBE (tabela II).

Esclarecemos, no entanto, que as escolas C, D e E que apresentaram maiores médias de respostas consideradas corretas quanto à indicação de IBE, foram aquelas que tiveram menores índices de alunos respondentes em relação aos números totais de alunos matriculados (Quadro IV).

Cumpre-nos ressaltar ainda, que isto não pode ser encarado como um critério isolado de avaliação da aprendizagem dos IBE, mesmo porque pode significar apenas a memorização dos termos, sem a real compreensão do seu significado contextual.

Este fato parece refletir-se nos conceitos de IBE emitidos pelos alunos quando, de maneira geral, foram pouco elucidativos, e nem sempre coincidentes com as respostas às demais questões.

Quanto aos IBE ministrados nas diversas escolas, observamos uma coerência entre as respostas de professores e alunos das escolas C, D e $E$, no que se refere, respectivamente, àqueles que foram ensinados $e$ àqueles apontados pelos alunos como IBE. Já nas escolas $A$ e $B$ os alunos indicaram um número de IBE inferior ao que foi ensinado. Inversamente, na escola $F$, os alunos citaram 06 instrumentos básicos, quando somente 01 deles (observação) foi ministrado.

A observação e a comunicação foram os IBE mais citados, pelos alunos das seis escolas de Enfermagem, tanto em relação à indicação dos IBE $(21,33 \%$ e $17,71 \%$ respectivamente; tabela III), quanto à sua utilização na prática $(28,08 \%$ e $16,72 \%$ respecitvamente, na tabela IV).

Paralelamente, estes são também os IBE considerados pelos professores como aqueles que oferecem menores dificuldades no processo ensino-aprendizagem e também como os mais utilizados pelos estudantes na prática.

A destreza manual e o planejamento também obtiveram índices significativos de citação pelos alunos, no que se refere aos aspectos já mencionados anteriormente $(12,68 \%$ para ambos na tabela III; $14,51 \%$ e $11,67 \%$ respectivamente na tabela IV). Estes dados podem estar relacio. nados à fase de desenvolvimento em que se encontravam os alunos, quando da coleta de dados ( $4 .^{\circ}$ semestre), devido à maior ênfase dada nesse período à aquisição de habilidades técnicas e elaboração do planejamento de cuidados.

Vale ressaltar que os professores também indicaram igualmente em 3. lugar, a destreza manual e o planejamento, como instrumentos mais utilizados pelo estudante na prática.

Quanto à importância dada aos IBE, notamos novamente uma coincidência entre alunos e professores relativa à observação e comunicação, 
quando apareceram também em maior freqüência nas quatro prioridades em que foram agrupadas as citações dos alunos, e quando mencionadas pela maioria dos professores das diversas escolas (5 e 4 indicações respectivamente).

Para os alunos, apareceram a seguir a destreza manual e o planejamento como os mais importantes, à semelhança do que ocorreu com os IBE considerados por eles como os mais utilizados na prática, em $3 .^{\circ}$ e $4 .^{\circ}$ indicações. Talvez isto possa ter sido motivado pelos mesmos fatores já comentados anteriormente.

Diferentemente, para os professores, o IBE citado como o mais importante, em $3 .^{\circ}$ lugar, foi o método científico. Apesar da valorização que os docentes deram à destreza manual e o planejamento na prática do estudante, eles pareceram priorizar o método científico, embora houvesse limitação nessa utilização, devido à própria fase de desenvolvimento em que se encontrava o aluno.

\section{CONCLUSÕES}

O estudo dos aspectos relacionados ao processo ensino aprendizagem dos IBE no curso de graduação das Escolas de Enfermagem da Grande São Paulo, permitiu as seguintes conclusões:

1. Em relação ao professor:

1.1. Os IBE foram ministrados no $2 .^{\circ}$ semestre do curso de graduação, nas disciplinas de Introdução ou Fundamentos de Enfermagem.

1.2. A carga horária total destinada ao ensino desses IBE variou de 7 a $50 \%$ da carga horária total da disciplina, sendo que metade das escolas distribuiu o ensino entre teoria e prática e as outras somente teórico.

1.3. As estratégias utilizadas pelos professores para o ensino teórico dos IBE foram baseados principalmente em aulas expositivas, estudos em grupo e seminários enquanto que para o ensino prático foram: a representação prática em campo de estágio e execução de técnicas em laboratório.

1.4. Os IBE ensinados nas escolas referiam-se aos preconizados por HORTA. A observação foi o único citado pelos professores, como ensinado nas seis escolas, comunicação, destreza manual, criatividade, aplicação dos princípios científicos, planejamento e trabalho em equipe foram citados pelos professores de 5 escolas. Avaliação e método científico foram os menos ensinados.

1.5. Os IBE mais empregados pelos alunos na prática foram observação e comunicação, enquanto o método científico e trabalho em equipe foram referidos como os menos empregados.

1.6. Os $I B E$, considerados mais importantes foram a observação, comunicação e método científico. 
1.7. Os objetivos do ensino dos $i B E$ segundo os professores estavam fundamentados na importância dos mesmos para o desenvolvimento profissional.

1.8. As dificuldades no ensino dos IBE mais citados pelos professores foram: dificuldade de bibliografia, necessidade de aplciação de conhecimentos de outras disciplinas e elevada proporção de alunos por professor.

2. Em relação ao aluno:

2.1. Os conceitos emitidos pelos alunos englobaram aspectos referentes a caracterização do termo IBE e aos objetivos da sua utilização na Enfermagem. A maioria dos estudantes conceituou IBE utilizando-se de termos com significado semelhante (sinonímia).

2.2. A maioria dos IBE identificados pelos alunos referiam-se aos preconizados por HORTA, sendo que os mais citados foram a observação e comunicação enquanto os menos citados foram: aplicação de princípios científicos, método científico ou de resolução de problemas e trabalho em equipe.

2.3. O IBE considerado como mais importante foi a observação, seguido pela comunicação, aplicação dos princípios científicos e planejamento.

2.4. Os IBE mais utilizados na prática foram a observação, a comunicação e destreza manual.

\section{CONSIDERAÇÕES FINAIS}

A ausência de estudos mais avançados sobre IBE nos últimos 20 anos, motivou-nos à elaboração deste estudo. A nossa proposição básica foi a de realizarmos um diagnóstico, mesmo que parcial, do processo ensino-aprendizagem desses instrumentos, nos Cursos de Graduação em Enfermagem em um núcleo representativo da profissão na comunidade brasileira.

O estudo possibilitou-nos atingir as seguintes considerações:

- Os IBE fazem parte dos conhecimentos programáticos das disciplinas de Introdução ou Fundamentos de Enfermagem das diversas Escolas da Grande São Paulo, apesar da considerável estagnação no aprofunda. mento de seus estudos;

- Os professores demonstram valorizar os IBE, quando se propõem a ensiná-los; manifestam sua preocupação quanto às inúmeras dificuldades existentes no ensino, e os priorizam no ensino e na prática;

- Os estudantes também confirmam essa valorização, quando expressam nos conceitos de IBE a sua importância para a profissão, quando os memorizam "já que a fixação de um evento reflete a atenção a ele dispensada e portanto o valor a ele atribuído" ${ }^{3}$ e quando reconhece a sua utilização na prática; 
- Existem várias dificuldades no processo ensino-aprendizagem dos IBE, que, na realidade, parecem fundamentar-se muito mais na ausência de uma melhor definição e caracterização dos IBE, pela falta de desenvolvimento teórico do assunto;

- Os IBE que se destacaram durante todo este estudo, foram a observação e a comunicação ressaltadas igualmente por docentes e por alunos, na teoria como na prática.

- Este fato parece refletir a caracterização, já histórica, do enfermeiro como um profissional "passivo", um "vigia" das condições do paciente, um "elo de ligação" dentro da equipe de saúde, com a conotação de que "observa e comunica" muito mais do que "atua" concreta e efetivamente junto ao cliente. ${ }^{4}$

A partir de todas essas considerações e reflexões, parece-nos propício elaborar algumas sugestões, que traduzem esperanças muito semelhantes àquelas que HORTA já revelava na década de 60, tais como:

- A necessidade da realização de estudos mais profundos acerca dos IBE, que caracterizam a sua importância para a formação e atuação profissional do enfermeiro; que testem e validem os instrumentos já consagrados como básicos para a Enfermagem, além da inserção de outros valores, atitudes, conhecimentos ou habilidades, dentro dos conceitos atualmente aceitos;

- A elaboração de um currículo de enfermagem integrado onde os IBE, uma vez validada a sua importância, o permeie e atue como um vínculo permanente na formação do estudante quer seja na graduação, na prática profissional posterior e mesmo na Pós-Graduação e

- Finalmente, que se crie uma metodologia prática, simples e econômica, que fundamente um processo ensino-aprendizagem efetivo.

FERRAZ, A. F.; DIOGO, M. J. D.; SOUZA, R. M. C. de; PEREZ, S. M.; SANTOS, V. L. C. de G.; MARIA, V. L. R. Basic instrument in nursing: aspects of teaching-apprenticeship process. Rev. Esc. Enf. USP, São Paulo, 22 (n. especial): 161-188, June, 1988.

The authors approach hov it has been developed the teaching of some instruments considered basic in Nursing practice. This study were realized with students and teachers from Grande São Paulo Nursing Schools.

UNITERMS: Nursing education. Nursing practical. Learning.

\section{REFERENCIAS BIBLIOGRÁFICAS}

1. HORTA, W. de A. Processo de enfermagem. São Paulo, EPU, 1979.

2. - HARA, Y.; PAULA, N. S. de. O ensino dos instrumentos básicos de enfermagem. Rev. Bras. Enf., Rio de Janeiro, 24(3/4):159-169, abr./jun. 1971.

3. MAGILL, R. A. Aprendizagem motora: conceitos e aplicações. São Paulo, Edgard Blucher, 1984. $273 \mathrm{p}$.

4. SOUZA, R. M. C. de et alii. Enfermagem: uma abordagem conceitual. Rev. Esc. Enf. USP, São Paulo, 20(3):229-35, dez. 1986. 


\author{
ANEXO I \\ UNIVERSIDADE DE SÃO PAULO \\ ESCOLA DE ENFERMAGEM \\ PROGRAMA DE PÓS-GRADUAÇÃO \\ NIVEL - MESTRADO
}

FORMULARIO PARA ENTREVISTA

Escola:

Disciplina: Introdução à Enfermagem

Fundamentos de Enfermagem

Outra nomenclatura:

Número de docentes na disciplina:

Carga horária total da disciplina:

Número de docentes para ministrar instrumentos básicos:

Segundo o conceito de HORTA: 'instrumentos básicos são as habilidades, conhecimentos e atitudes indispensáveis para a execução de uma atividade". Assim:

1. Os instrumentos básicos de enfermagem fazem parte do conteúdo programático da disciplina de Introdução à Enfermagem ou Fundamentos de Enfermagem?

$\operatorname{Sim}()$

Não ( )

2. Quais os instrumentos básicos de enfermagem que são ensinados?

3. Quais as estratégias empregadas para o ensino dos instrumentos básicos:

- Na teoria:

- carga horária:

- Na Prática (laboratório e campo): 
4. Quais as dificuldades encontradas no processo ensino-aprendizagem desses instrumentos básicos? (Especificar por instrumento se necessário).

5. AVALIAÇAO: - análise do comportamento do paciente

6. Quais os instrumentos básicos de enfermagem que você considera que o aluno mais emprega na prática?

7. Quais são os instrumentos básicos que os professores da sua disciplina consideram mais importantes? 


$$
\begin{gathered}
\text { ANEXO II } \\
\text { UNIVERSIDADE DE SÃO PAULO } \\
\text { ESCOLA DE ENFERMAGEM } \\
\text { PROGRAMA DE POS-GRADUAÇÃO } \\
\text { NIVEL — MESTRADO }
\end{gathered}
$$

\section{QUESTIONARIO PARA ALUNOS DA GRADUAÇÃo}

1. O que você entende por instrumentos básicos da enfermagem?

2. Quais são os instrumentos básicos da enfermagem?

3. Enumere os instrumentos básicos começando do mais importante para o menos importante:

4. Quais são os instrumentos básicos que você mais utiliza na prática? 


\section{ANEXO III}

\section{RESPOSTAS QUE COMPUSERAM OS “ITENS RELACIONADOS AOS IBE"}

1. OBSERVAÇÃO: - observação visual

- percepção

- atenção

- observação das necessidades humanas básicas

- observação do paciente

2. COMUNICAÇÃO: - diálogo

- passagem de plantão

3. DESTREZA MANUAL: - agilidade

- precisão

- eficiência

4. PRINCíPIOS CIENTífICOS: - princípios básicos

- conhecimento técnico-científico

- aplicação científica

- embasamento científico

- conhecimento de técnica

- conhecimento teórico-prático

- estudo de caso

- conhecimento científico

5. AVALIAÇÃO: - análise do comportamento do paciente

- análise dos dados

- reavaliação

6. METOdO CIENTífICO: - pesquisa científica

- trabalho científico

7. TRABALHO EM EQUIPE: - equipe de enfermagem

8. PlANeJAMENTO: - organização

- planejamento de atividades

9. CRIATIVIDADE: - improvisação 


\section{ANEXO IV}

\section{RESPOSTAS COMPONENTES DOS "ITENS NAO-RELACIONADOS AOS IBE"}

1. Fases da Metodologia Assistencial proposta por HORTA

1.1. Histórico de Enfermagem

- levantamento de dados

- palpação

- ausculta

- ausculta cardíaca

- olfato

- audição

- conhecimento físico

Exame físico

1.2. Plano Assistencial (FAOSE)

- ajudar

- orientar

- encaminhar

- ensinar

- informar

1.3. Plano de cuidados

- planejamento do plano de cuidados

- execução dos cuidados de enfermagem

- realizar

- atuação

- anotação

1.4. Atendimento das necessidades humanas básicas

- preparo do paciente

- higiene

- atendimento das necessidades físicas e emocionais do paciente

- conforto e segurança

- psicoespiritual

- psicobiológico

- apoio biopsicoespiritual

- atendimento das necessidades humanas básicas

2. Valores e atiudes da enfermagem

- amor

- dedicação

- calma

- vocação

- postura

- disponibilidade

- responsabilidade

- respeito

- honestidade

- ética profissional 
- carinho

- vontade

- predisposição

- reconhecimento do dever

- desprendimento

- iniciativa

- interesse

- liderança

- identificação

- contribuição

- valorização

3. Materiais e equipamentos

- estetoscópio

- esfigmomanômetro

- termômetro

- balança

- garrote

- tesoura

- medicamentos

- relógio 